\title{
MORFOLOGIA E CRESCIMENTO DOS 6 AOS 10 ANOS DE IDADE EM VIANA DO CASTELO, PORTUGAL
}

\author{
GROWTH OF 6- TO 10-YEARS-OLD CHILDREN \\ FROM VIANA DO CASTELO, PORTUGAL
}

\author{
AUTORES \\ Luis Paulo Rodrigues ${ }^{1}$ \\ Pedro Bezerra ${ }^{2}$ \\ Linda Saraiva ${ }^{2}$ \\ ${ }^{1}$ Instituto Politécnico de Viana do Castelo \\ e LIBEC, Portugal \\ ${ }^{2}$ Instituto Politécnico de Viana do Castelo, \\ Portugal
}

MORFOLOGIA E CRESCIMENTO DOS 6 AOS 10 ANOS DE IDADE EM VIANA DO CASTELO, PORTUGAL 4(3): 25-39

\section{PALAVRAS-CHAVE}

crescimento; crianças; aptidão morfológica; somatótipo.

\section{KEYWORDS}

growth; children; somatic fitness; somatotype.

\section{RESUMO}

Ao longo de quatro anos, o Estudo Morfofuncional da Criança Vianense observou 1911 crianças entre os 6 e os 10 anos de idade, resultando em 4064 observações individuais (2054 de raparigas, 2006 de rapazes). Os resultados encontrados nos indicadores morfológicos simples (altura, peso, pregas adiposas, diâmetros ósseos e perímetros musculares) e no somatótipo, são descritos normativamente (valores percentílicos) e comparados com outros estudos nacionais e internacionais.

As crianças vianenses demonstraram possuir uma estatura média ligeiramente superior às reportadas nos estudos portugueses e um ritmo de crescimento diferente das norte-americanas; peso semelhante ao das congéneres nacionais mas inferior ao das EUA; valores de pregas adiposas geralmente inferiores aos encontrados em Portugal e EUA; perímetros musculares e diâmetros ósseos semelhantes aos seus pares portugueses; e uma tendência para o aumento, com a idade, do ectomorfismo nos rapazes e do endomorfismo em ambos os sexos. Este panorama parece indicar que as crianças vianenses apresentam características de aptidão morfologia que estão longe de espelhar as preocupações internacionais nesta matéria.
ABSTRACT

In the Estudo Morfofuncional da Criança Vianense, 1911 elementary school children were measured throughout a four year period, resulting in 4064 individual observations of 6 to 10 year-old children (2054 girls, 2006 boys). The anthropometric variables (height, weight, skinfolds, muscle girth and bone breadth] were used to create percentile reference tables for the local population, and to study their somatotypes in relation to somatic fitness. The results were compared with other national and international studies.

Viana's children averaged similar height, weight, muscular girths and bone breadths when compared with other Portuguese studies, but revealed a different growth rhythm and lower weight than the US children. Their skinfolds were also smaller than the reported values for Portugal and for the US. Throughout the elementary school time span, there tended to be an increase in the ectomorphy component for boys, and in the endomorphy for both genders.

In conclusion, Viana's children growth characteristics appear to indicate a level of somatic fitness that is far from mirroring today's international concerns regarding this matter. 


\section{INTRODUCÃO}

0 estudo das características morfológicas e do crescimento das crianças e jovens tem assumido ao longo dos tempos uma importância fundamental na compreensão das condições de desenvolvimento das populações. 0 estabelecimento de normas percentílicas de crescimento, para além da sua ampla utilização no campo pediátrico, epidemiológico, e nutricional, tem permitido aos pais perceber meIhor o crescimento dos seus filhos, e fornecido aos educadores um instrumento importante para a análise dos percursos de desenvolvimento das crianças e jovens. Nos adultos, a associação entre as características morfológicas e o desempenho motor (e desportivo), os níveis de actividade física, os estilos de vida adoptados, e a saúde dos indivíduos, é cada vez mais evidente nas sociedades modernas. Desde logo este facto leva à necessidade de percebermos as características e os ritmos de mudança[s] morfológicas nas nossas populações infanto-juvenis, quer como prenúncio [ou prevenção] dos problemas futuros, quer para detecção e promoção da aptidão morfológica como factor de sucesso do desempenho desportivo. A compreensão plena deste fenómeno passa não só pelo levantamento dos indicadores morfológicos simples (altura, peso, etc.] mas também pelo conhecimento relativo a indicadores morfológicos mais complexos tais como o somatótipo.

0 crescimento estatural é um dos indicadores simples mais utilizados para avaliar o estado de desenvolvimento dos indivíduos e das populações. A saúde, nutrição, e bem-estar de uma sociedade reflecte-se na sua média estatural e na forma como evolui ao longo dos tempos (fenómeno conhecido como tendência secular de crescimento]. Ao mesmo tempo, habituámo-nos já a reconhecer que a posição relativa (percentílica) de uma criança no seio da sua população e ao longo do crescimento, constitui informação fundamental para a avaliação do seu desenvolvimento. A massa corporal, directamente medida pelo peso, constitui uma forma simples e valiosa de retirar informações acerca das condições de nutrição dos indivíduos e populações ao longo do crescimento. No entanto o peso não nos dá indicações sobre a identidade dos diferentes constituintes implicados (músculo, osso, adiposidade, água, vísceras, etc.], pelo que as ilações acerca do peso da(s) criança(s) devem ser criteriosas. Os perímetros musculares dão-nos indicações acerca da contribuição da componente muscular na morfologia corporal e os diâmetros bicôndilo umeral e femural permitem avaliar a contribuição da estrutura óssea na morfologia das crianças. Estas medidas (e principalmente o primeiro] são reconhecidamente indicadores das dimensões em largura e robustez do esqueleto $^{10}$. Por sua vez, o somatótipo permite representar o compósito morfológico de um indivíduo segundo a contribuição de três componentes principais: o endomorfismo representa a deposição de massa adiposa corporal; o mesomorfismo traduz o desenvolvimento músculo-esquelético em relação à altura; e o ectomorfismo expressa a linearidade, ou seja a relação entre o volume de massa corporal e a altura do indivíduo. 0 princípio da existência de uma estreita relação entre a performance e a morfologia é geralmente aceite pela maioria dos estudiosos da matéria ${ }^{12,27}$. Todos os desportistas têm como componente dominante o mesomorfismo. 0 mesomorfo é solidamente musculado, a sua força e robustez física conferem-lhe uma aptidão particular para a prática desportiva, sendo geralmente o ecto-mesomorfismo que caracteriza o desportista confirmado e em plena actividade ${ }^{1,2}$. Os jovens atletas são em geral menos mesomórficos, menos endomórficos e mais ectomórficos do que os atletas adultos, centrando-se nas categorias ecto-mesomórficos, ectomorfos-mesomórficos e mesoectomórficos ${ }^{1,4}$. Hoje sabemos que a participação e entrada voluntária num determinado desporto esta habitualmente também dependente da existência de um somatótipo apropriado $^{3}$ o que aconselha o conhecimento da configuração morfológica e sua evolução nos estudos das populações infanto-juvenis.

Em Portugal a preocupação de levantamentos caracterizadores destes aspectos não tem sido de todo evidente. Salvo honrosas excepções $^{14,15,16,23,24,28}$, a produção científica nacional nesta matéria é reduzida, pouco consistente e nunca sistemática. Esta lacuna explica não só o recurso obrigatório às informações dos estudos internacionais, mas sobretudo o nosso profundo desconhecimento da população nacional e suas características regionais, inviabilizando assim as possibilidades de antevisão e preparação do futuro. Nos bons exemplos internacionais ${ }^{8,18,19}$ esta tarefa de levantamento e diagnóstico das condições morfológicas (e nutricionais) das populações é assumida pelo estado como peça de informação fundamental na determinação das políticas de saúde e educação.

Partindo destas preocupações, o Departamento de Motricidade Hu- 
mana da Escola Superior de Educação do Instituto Politécnico de Viana do Castelo (ESEVC) iniciou no ano de 1997 um largo estudo de caracterização das crianças do concelho de Viana do Castelo: o Estudo Morfofuncional da Criança Vianense (EMCV). São os resultados relativos ás variáveis de crescimento morfológico que apresentamos neste artigo com o intuito de as caracterizar normativamente na população infanto-juvenil do concelho, e avaliar a aptidão morfológica dos perfis exibidos pelas crianças e jovens vianenses de acordo com os critérios e valores referenciados para jovens destas idades.

\section{METODOLOGIA}

\section{Amostra}

A amostra utilizada neste estudo pertence ao EMCV, investigação que decorreu de 1997 a 2000 e que recolheu dados morfológicos, bio-sociais e de aptidão física de 2386 crianças pertencentes a quinze escolas do $1^{\text {o }}$ Ciclo do Ensino Básico (1CEB) de Viana do Castelo. A escolha destas escolas obedeceu a critérios de localização geográfica e representatividade equitativa de idades, género e ambiente socio-económico. As duas escolas mais populosas (Avenida e Carmo) situavam-se no centro da cidade de Viana do Castelo (626 Rapazes, 612 raparigas]. As restantes treze (568 Rapazes; 580 raparigas] encontravam-se dispersas no tecido ruralizado do Concelho ${ }^{13}$ (Portelas e São Gil [Perre], Cardielos, Outeiro, Nogueira, Serreleis, Samonde, Deocriste, Santa Maria de Geraz do Lima, São Salvador da Torre, Subportela, Vila Mou e Deão].
Durante os quatro anos em que decorreu o EMCV, todas as crianças pertencentes às escolas seleccionadas foram observadas anualmente. No total foram realizadas 4251 observações (2127 de raparigas, 2124 de rapazes] entre os 6 e os 17 anos de idade. Neste artigo são apenas apresentados os resultados relativos às idades mais usuais para alunos do 1CEB, entre os 6 e os 10 anos completos lex: consideram-se com 6 anos desde os 6.0 até aos 6.9 anos decimais), o que resultou em 4064 observações individuais (2054 de raparigas, 2006 de rapazes] correspondendo a um total de 1911 crianças [644 foram observados num único ano, 573 em dois anos, 502 em três anos, e 192 foram observados em quatro anos consecutivos). Esta configuração mista (longitudinal e transversal] da amostra permite-nos falar dos resultados na perspectiva do crescimento com alguma segurança, já que a quantidade de crianças que foram alvo de observacões repetidas é importante.

\section{Procedimentos}

As variáveis morfológicas (antropométricas] foram escolhidas de forma a poderem ser usadas como marcadoras complementares do desenvolvimento morfológico das crianças. Foram assim medidas a altura (ALT), o peso (PESO), as pregas adiposas tricipital (SKTRI), sub-escapular (SKSBS), suprailíaca (SKSIL), e geminal (SKGML), os perímetros do braço com contracção (PRBC) e geminal (PGML), e os diâmetros bicôndilo-umeral (DBCU) e bicôndilo-femural (DBCF). Os valores recolhidos foram introduzidos nas fórmulas de cálculo do somatótipo, segundo o método Heath-Carter ${ }^{5}$.
A recolha de dados decorreu anualmente durante os meses de Abril e Maio nas instalações da ESEVC. As escolas, após terem sido obtidas autorizações do Centro de Área Educativa de Viana do Castelo e dos pais das crianças, deslocaram-se com o apoio de autocarros pertencentes à Câmara Municipal de Viana do Castelo, e, durante uma manhã cada criança percorreu um circuito de mensuração antropométrica que decorreu num ginásio e cuja ordem de execução foi: ALT, PESO, SKTRC, SKSBS, SKSIL, SKGML, DBCU, DBCF, PBRC, PGML.

A execução das medidas obedeceu aos protocolos descritos no Anthropometric Standardization Reference Manual $^{21}$ e todos os procedimentos utilizados no EMCV respeitaram as normas internacionais de experimentação com humanos, expressas na Declaração de Helsínquia de 1975. Os componentes da equipa de observação eram alunos finalistas do Curso de Educação Física com formação em antropometria e foram previamente sujeitos a sessões de treino nas suas tarefas específicas. Cada observador foi responsável por uma só das medidas registadas e todos os momentos foram supervisionados pelo primeiro autor, de forma a assegurar a qualidade do processo. Uma em cada doze crianças foi escolhida aleatoriamente para repetir a execução de todas as medidas com a finalidade de aferirmos a fidelidade da avaliação. Os coeficientes de correlação intra-classe $^{26}$ resultantes desta repetição são apresentados no quadro 1.

Os dados finais, após introdução numa base de dados informatizada, foram submetidos a um processo exploratório de detecção de erros. 


\begin{tabular}{lccccc} 
& \multicolumn{5}{c}{ Anos de recolha } \\
Variáveis & 1997 & 1998 & 1999 & 2000 & $1997 / 2000$ \\
\cline { 2 - 6 } & $(n=67)$ & $(n=55)$ & $(n=65)$ & {$[n=61)$} & {$[n=248)$} \\
\hline ALT & .99 & .96 & .99 & .99 & .98 \\
PESO & .99 & .99 & .98 & .99 & .99 \\
SKTR & .97 & .98 & .96 & .99 & .98 \\
SKGML & .98 & .99 & .96 & .99 & .98 \\
SKSBS & .97 & .98 & .99 & .99 & .99 \\
SKSPIL & .99 & .99 & .96 & .98 & .98 \\
DBCU & .94 & .97 & .98 & .99 & .97 \\
DBCF & .96 & .99 & .99 & .99 & .98 \\
PBCC & .99 & .99 & .99 & .99 & .99 \\
PGEM & .99 & .78 & .91 & .87 & .88 \\
\hline & \multicolumn{7}{r}{} & NOTA: Os CCI indicados são de tipo 3,1 geralmente referidos \\
& .99 & como medidas simples de correlação intraclasse.
\end{tabular}

QUADR01

Valores do Coeficiente de Correlação Intraclasse para cada variável por ano de recolha e total agregado.

0 registo de distribuição de cada variável foi analisado e todos os valores detectados como extremos foram reconfirmados nos registos originais e corrigidos ou apagados (nos casos em que existia erro evidente no registo original].

\section{Estatística}

O comportamento de cada variável nas diferentes idades e segundo o sexo, é descrito através dos valores da média ( $M)$, desvio-padrão (DP) e percentílicos ( $p 05, p 10$, p25, p50, p75, p90, e p95]. No caso das pregas adiposas, e porque que a distribuição amostral dos resultados se revelou assimétrica, é também apresentada a média robusta lestimada pelo procedimento Huber's M-Estimator] sendo este o valor utilizado nas representações gráficas. Esta opção foi tomada para assegurar maior ajustamento da média à população, já que a grande assimetria da dis- tribuição dos valores destas variáveis originaria médias reais mais elevadas mas desajustadas da realidade. Para compararmos os valores ocorridos na nossa população com os outros estudos apresentados foram efectuados testes $t$ -Student para cada escalão etário, recorrendo aos valores das médias, desvios padrão e do número de indivíduos testados (valores não apresentados neste artigo para os outros estudos]. Os cálculos descritivos foram feitos no programa estatístico SPSS 11.0. Os testes $t$ -Student foram realizados no software GraphPad gratuitamente disponível na Internet (www.graphpad.com).

\section{RESULTADOS}

Neste ponto começamos por apresentar os valores de ALT e PESO, agregando depois as variáveis relativas à adiposidade (SKTRI, SKSBS,
SKSIL, SKGML], as marcadoras do desenvolvimento muscular (PBRC e PGML], e as da robustez esquelética (DBCU e DBCF). Por último são apresentados os valores relativos à classificação somatotipológica. A análise efectuada centra-se na descrição e comparação dos percursos de desenvolvimento para os rapazes e raparigas. Para tal foram utilizados valores recolhidos na população portuguesa em estudos contemporâneos com valores amostrais de grande dimensão, nomeadamente o Estudo de crescimento da Maia ${ }^{24}$, o Estudo de crescimento da Madeira ${ }^{9}$, o Estudo do crescimento somático, aptidão física e capacidade de coordenação corporal de crianças do 1 o Ciclo do Ensino Básico da Região Autónoma dos Acores ${ }^{14,15,16}$, a Reavaliação antropométrica da população infantil de Lisboa $^{28}$, e os resultados relativos a dados de Portugal Continental $^{23}$. No intuito de percebermos também as mudanças ocorridas no crescimento somático da população Vianense ao longo das últimas quatro décadas, é feita a comparação com os Estudos sobre o desenvolvimento da criança portuguesa em idade escolar ${ }^{25}$, levado a cabo entre 1971-1981. Nas comparações internacionais optamos por utilizar apenas os valores dos EUA relativos ao National Health and Nutrition Examination Survey (NHANES) já que são os valores normativos usualmente adoptados para a população pediátrica portuguesa pelo Sistema Nacional de Saúde. Os resultados citados neste estudo referem-se ao NHANES $I I^{20}$, realizado no período 1988-94, e aos resultados já disponíveis do período 1999-2002 do NHANES IV ${ }^{17}$. Durante todo o artigo, e para uma datação mais rigorosa das comparacões, procuramos utilizar as datas relativas ao último ano da recolha de 
dados dos estudos citados. Quando estas não são referidas pelos autores são utilizadas as datas de publicação dos resultados.

\section{Altura}

Na população infanto-juvenil de Viana do Castelo (figura 1 e quadro 2), rapazes e raparigas apresentaram valores médios muito semelhantes em cada intervalo etário.

Comparando com os valores recoIhidos no concelho em 1981 por Ribeiro Rosa, constatamos que a altura média dos rapazes e raparigas aumentou cerca de $10 \mathrm{~cm}$ nos últimos 30 anos $(p<.001$ para todas as idades), sendo hoje idêntica às médias das crianças lisboetas e às do Concelho da Maia. Relativamente às crianças das ilhas (Madeira e Açores] as nossas crianças apresentam valores médios estaturais ligeiramente superiores, assumindo estas diferenças um valor estatisticamente significativo em quase todas as idades (ver quadro 2). 0 mesmo fenómeno acontece com os dados reportados para Portugal Continental aos oito e nove anos de idade para ambos os sexos. Comparativamente aos valores estimados na população norte-americana pelo NHANES IV em 2002, as nossas crianças apresentam-se em média cerca de $2 \mathrm{~cm}$ (rapazes) e $3 \mathrm{~cm}$ (raparigas) mais altos aos 6 anos ( $p<.001$ ), no entanto essa diferença esbate-se logo nos escalão etário seguinte ( 7 anos), passando as crianças norte-americanas a serem significativamente mais altas que as vianenses $(p<.05$ aos 8 e 9 anos masculinos; $p<.001$ aos 10 anos femininos].

\section{Peso}

Na população vianense, rapazes e raparigas apresentaram valores médios de peso muito semelhantes

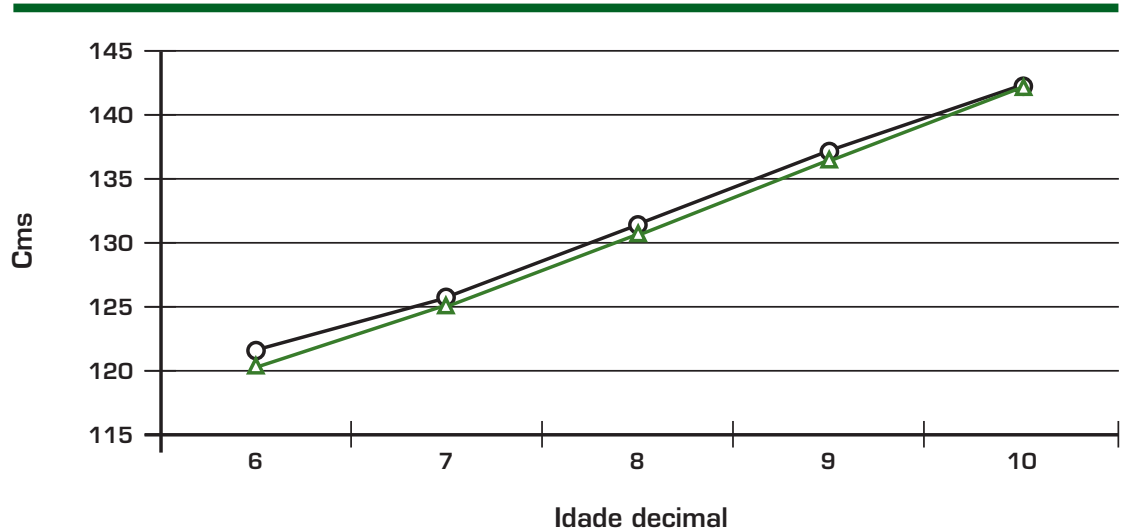

LEGENDA

$\triangle-$ Feminino $\quad-\circ-$ Masculino

Médias de altura de rapazes e raparigas do EMCV entre os 6 e os 10 anos. entre os 6 e os 10 anos, aumentando entre 2.4 a $3.4 \mathrm{~kg}$ por ano (figura 2 e quadro 3). Isto quer também dihoje mais do que em 1981, e quanto mais velhos maior a diferença zer que as nossas crianças pesam [de cerca de $5 \mathrm{~kg}$ aos 7 anos para $8 \mathrm{~kg}$ aos 10 anos; $\mathrm{p}<.001$ para todas as idades e sexos].

Estes valores actuais são muito semelhantes aos encontrados hoje na Maia e em Portugal continental

\begin{tabular}{|c|c|c|c|c|c|c|c|c|c|c|}
\hline \multirow[b]{2}{*}{ Idade } & \multicolumn{5}{|c|}{ Masculino } & \multicolumn{5}{|c|}{ Feminino } \\
\hline & 6 & 7 & 8 & 9 & 10 & 6 & 7 & 8 & 9 & 10 \\
\hline$N$ & 325 & 501 & 487 & 454 & 239 & 318 & 499 & 514 & 489 & 234 \\
\hline p95 & 129.7 & 135.4 & 140.5 & 146.0 & 151.0 & 128.9 & 134.9 & 140.5 & 146.3 & 152.1 \\
\hline p90 & 127.9 & 133.5 & 138.6 & 144.3 & 148.7 & 127.2 & 133.2 & 138.5 & 144.1 & 149.1 \\
\hline p75 & 124.8 & 129.5 & 135.2 & 140.7 & 143.8 & 124.3 & 128.9 & 135.0 & 140.5 & 144.5 \\
\hline p50 & 121.1 & 125.4 & 131.2 & 136.5 & 139.9 & 120.0 & 125.0 & 130.5 & 135.9 & 139.8 \\
\hline p25 & 117.5 & 121.8 & 127.4 & 132.5 & 135.9 & 116.7 & 120.9 & 126.8 & 131.7 & 135.6 \\
\hline p10 & 115.1 & 118.5 & 123.8 & 128.8 & 131.8 & 113.5 & 118.1 & 123.2 & 128.6 & 132.6 \\
\hline p05 & .2 & 116.7 & 122.1 & 127.1 & 5 & .8 & 116.4 & 21.6 & 127.0 & 130.7 \\
\hline$M$ & 121.3 & 125.7 & 131.3 & 136.6 & 140.2 & 120.2 & 125.2 & 130.8 & 136.2 & 140.3 \\
\hline DP & 5.0 & 5.5 & 5.8 & 5.8 & 6.4 & 5.3 & 5.6 & 5.9 & 6.0 & 6.5 \\
\hline Viana 81 & - & $115.9^{\star \star}$ & $121.3^{\star \star}$ & $126.4^{\star \star}$ & $131.5^{\star *}$ & - & $115.7^{\star \star}$ & $120.2^{\star \star}$ & $125.1^{* *}$ & $130.3^{\text {** }}$ \\
\hline Maia O० & $119.9^{\star *}$ & 124.9 & 130.9 & 136.6 & - & 119.2 & 125.5 & 129.7 & 136.6 & - \\
\hline Lisboa 01 & 120.1 & 125.5 & 131.3 & 136.1 & $138.9^{*}$ & 118.0 & 122.4 & 128.2 & 133.2 & 137.5 \\
\hline Açores 02 & 120.3 & 125.1 & 130.5 & $135.3^{\text {** }}$ & $138.5^{\star *}$ & 120.2 & $124.3^{*}$ & $129.9 *$ & $135.0^{* *}$ & $139 *$ \\
\hline Madeira 02 & - & - & 129.7 & $135.3^{*}$ & $139.0^{*}$ & - & - & $128.4^{\text {** }}$ & $134.3^{\star *}$ & $138.2^{\star \star}$ \\
\hline Portugal 02 & - & 126.0 & $129.9^{* *}$ & $135.3^{\text {* }}$ & - & - & 124.9 & $129.4^{\text {** }}$ & $134.7^{\star *}$ & - \\
\hline EUA 02 & $119,2^{* *}$ & 126.2 & $132.5^{*}$ & $138.1^{\text {** }}$ & 141.4 & $117.1^{\star \star}$ & 124.4 & 130.9 & 136.9 & $143.3^{\star \star}$ \\
\hline
\end{tabular}




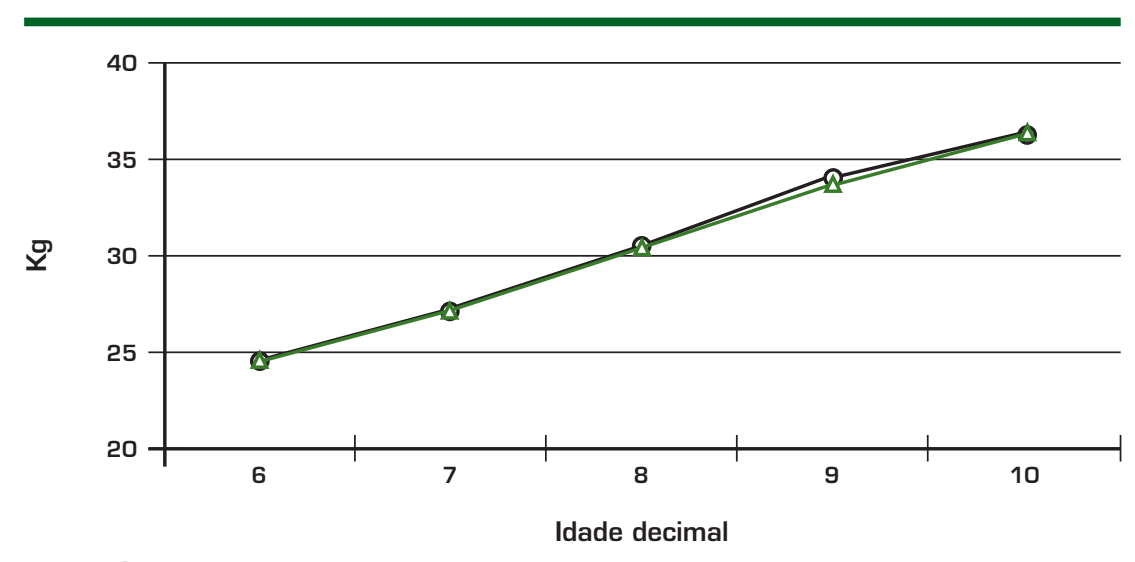

FIGURA2

Médias do peso de rapazes e raparigas do EMCV entre os 6 e os 10 anos.

LEGENDA

$\triangle-$ Feminino $\quad-$ - Masculino

(entre 7 e os 9 anos); ligeiramente inferiores (cerca de $1 \mathrm{~kg}$ ) aos da população açoriana, mas cerca de 2 a $3 \mathrm{~kg}$ superiores aos valores reportados na Madeira $(p<.001$ para todas as idades e sexos).

Comparativamente com as médias reportadas para os EUA em 2002, as nossas crianças começam por ser mais pesados aos seis anos ( $p<.001$ ), para passarem progressivamente a exibir valores significati-

\begin{tabular}{|c|c|c|c|c|c|c|c|c|c|c|}
\hline \multirow[b]{2}{*}{ Idade } & \multicolumn{5}{|c|}{ Masculino } & \multicolumn{5}{|c|}{ Feminino } \\
\hline & 6 & 7 & 8 & 9 & 10 & 6 & 7 & 8 & 9 & 10 \\
\hline$N$ & 325 & 501 & 486 & 454 & 239 & 318 & 501 & 513 & 488 & 235 \\
\hline p95 & 34.0 & 36.6 & 42.1 & 47.3 & 51.6 & 34.0 & 38.0 & 42.0 & 46.8 & 51.7 \\
\hline p90 & 30.5 & 34.5 & 39.0 & 43.0 & 49.0 & 31.0 & 35.0 & 39.0 & 43.1 & 48.0 \\
\hline p75 & 26.5 & 30.0 & 34.0 & 38.0 & 41.0 & 27.0 & 30.0 & 34.0 & 38.0 & 41.9 \\
\hline p50 & 24.0 & 26.0 & 29.5 & 32.5 & 34.5 & 23.5 & 26.0 & 29.5 & 33.0 & 35.0 \\
\hline p25 & 21.5 & 23.5 & 26.0 & 29.0 & 30.5 & 21.0 & 23.0 & 26.0 & 28.0 & 30.0 \\
\hline p10 & 20.5 & 22.0 & 24.0 & 26.5 & 28.0 & 19.5 & 21.5 & 24.0 & 26.0 & 27.5 \\
\hline p05 & 20.0 & 21.0 & 22.5 & 25.0 & 27.0 & 18.5 & 20.0 & 22.0 & 24.5 & 26.7 \\
\hline$M$ & 24.7 & ᄃl. & 30.6 & 34.0 & 36.5 & 24.7 & 27.2 & 30.4 & 33.8 & 36.7 \\
\hline DP & 4.6 & 5.3 & 6.2 & 6.8 & 8.2 & 5.0 & 5.4 & 6.4 & 7.0 & 8.1 \\
\hline ana 81 & - & $21.3^{* *}$ & $23.6^{\text {** }}$ & $26.0^{\star *}$ & $28.4^{* *}$ & - & $21.8^{* *}$ & $23.8^{* *}$ & $26.5^{* *}$ & $29.3^{\star *}$ \\
\hline Maia O० & 24.5 & 27.1 & 31.8 & 34.7 & - & 24.8 & 27.4 & 29.7 & 34.8 & - \\
\hline Lisboa 01 & 23.4 & 26.4 & 29.5 & 32.9 & 33.9 & 23.5 & 25.5 & 29.4 & 33.3 & 36.1 \\
\hline Açores 02 & 24.8 & 27.5 & 30.8 & 34.1 & 36. & 25.0 & 27.1 & 30.1 & 34.5 & 36.8 \\
\hline Madeira 02 & - & - & 27.9 ** & $31.2^{\star \star}$ & $33.5^{\text {** }}$ & - & - & $27.2^{\star \star}$ & $30.7^{\text {** }}$ & $33.0^{* *}$ \\
\hline Portugal 02 & - & 27.1 & 30.2 & 33.9 & - & - & 27.3 & 30.3 & 33.3 & - \\
\hline EUA 02 & $23.5^{\text {** }}$ & 27.2 & $32.7^{\text {** }}$ & $36.0^{\star *}$ & 38.6 * & $22.4^{\text {** }}$ & $25.9^{\star \star *}$ & 31.9 & $35.4^{*}$ & 40.0 ** \\
\hline
\end{tabular}

\section{QUADRO3}

Valores percentílicos, média e desvio-padrão do Peso no EMCV

e médias de outros estudos nacionais e internacionais.

${ }^{*} p<.05{ }^{* *} p<.001$ vamente menores de massa corporal a partir dos oito anos $(p<.001$ para os rapazes aos 8,9 e 10 anos, e para as raparigas aos 9 anos].

\section{Pregas adiposas}

Neste artigo apresentamos os resultados de quatro pregas adiposas distribuídas por três regiões corporais: membros superiores (SKTRI), tronco [SKSBS e SKSIL] e membros inferiores (SKGML). Dada a assimetria das distribuições encontradas, as médias aritméticas originariam valores desajustados (mais elevadas) da representação real da criança média, pelo que nos quadros 4, 5, 6 e 7 e nos gráficos da figura 3 são apresentadas as médias robustas lestimadas pelo procedimento Huber's M-Estimator].

Pela análise da figura 3 e dos quadros 4 a 7, facilmente se comprova que as raparigas possuem sempre valores mais elevados em todas as pregas. As pregas adiposas das crianças vianenses aumentam ligeiramente ao longo dos cinco anos estudados, demonstrando tendência para serem mais volumosas nas extremidades (SKTRI e SKGML) do que no tronco [SKSIL e SKSBS]. $\mathrm{Na}$ prega tricipital as crianças vianenses apresentam valores médios mais baixos do que a amostra nacional e as congéneres maiatas ( $p<.0001$ ), e lisboetas (valores significativos para os rapazes aos 6 e 8 anos, e raparigas aos 6, 8 e 9 anos). Os rapazes vianenses possuem pregas adiposas tricipitais semelhantes aos rapazes da Madeira, mas as raparigas evidenciam valores ligeiramente mais elevados do que as madeirenses $(p<.01$ aos 9 anos]. Em comparação com a população infantil norte-americana 
em 2002 as nossas crianças exibem uma prega tricipital significativamente inferior nos rapazes em todas as idades $(p<.05$ aos 7 anos, $\mathrm{p}<.001$ nas restantes], e nas raparigas a partir dos oito anos de idade $(p<.05)$.

$\mathrm{Na}$ avaliação da prega geminal apenas foi possivel compararmos a nossa amostra com a população infantil de Lisboa, da Maia e da Madeira. Nos dois primeiros casos os valores masculinos e femininos são muito semelhantes aos de Viana, enquanto no terceiro mostram maiores pregas geminais nas crianças do EMCV, com especial ênfase para as raparigas $(p<.02)$.

Relativamente à prega sub-escapular não foram encontradas diferencas relevantes entre a nossa população e a lisboeta, a madeirense, ou as raparigas da Maia. 0 mesmo já não pode ser dito quanto aos valores reportados por Padez e colaboradores na amostra nacional, já que as nossas crianças tiveram pregas significativamente inferiores $\{p<.02$ para todos os valores à excepção dos 7 anos masculinos), com especial relevância para o sexo feminino onde a diferença média chega quase aos $5 \mathrm{~mm}$. Também na Maia os rapazes apresentaram pregas subescapulares de maiores dimensões ( $p<.05$ aos 6 e 7; $p<.001$ aos 8 e 9 anos).

Na dimensão da prega suprailíaca, a população vianense obteve medidas não muito diferentes das madeirenses, mas inferior à maiata ( $>$.001), e à lisboeta em praticamente todas as idades, e em particular no sexo feminino $(p<.05$ dos 6 aos 9 anos). e maiata. Esta diferença acontece também ( $p<.05$ aos 9 anos) quando nos comparamos com os valores norte-americanos do NHANES III.

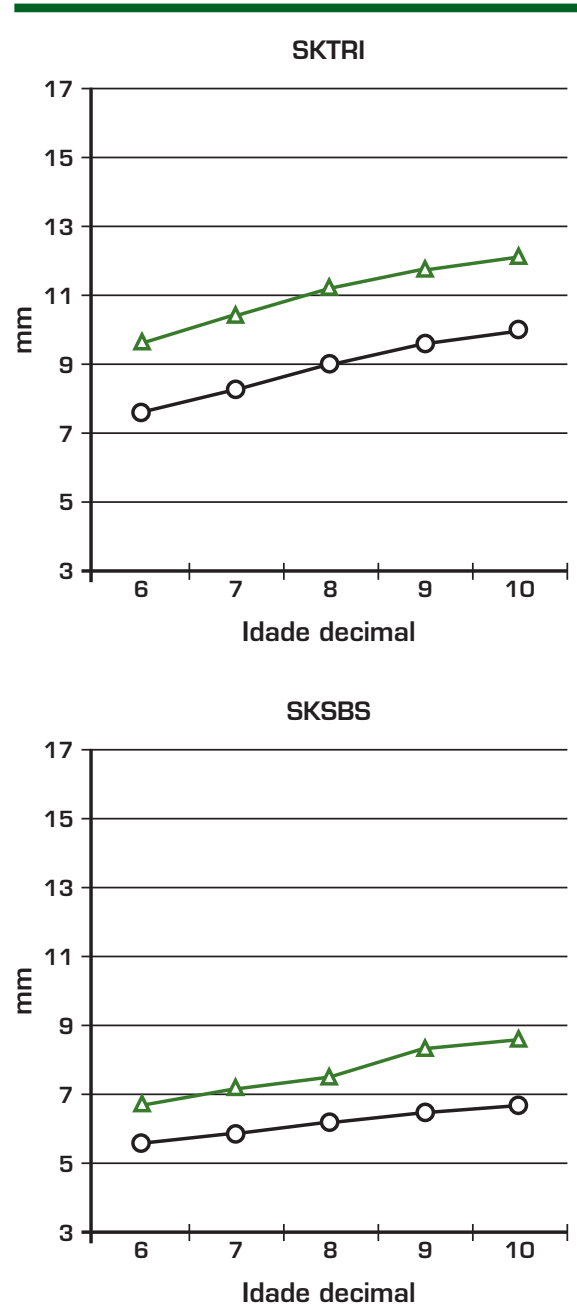

SKGML

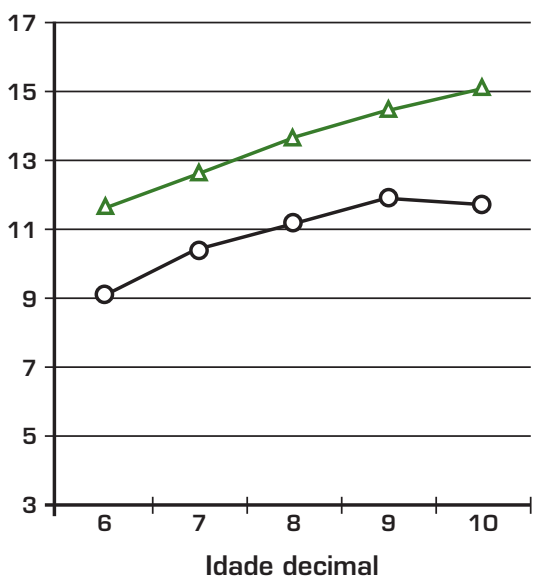

SKFSIL

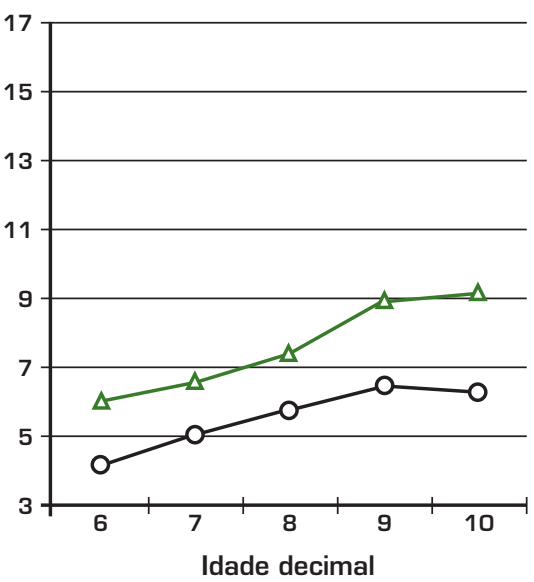

FIGURA3

LEGENDA

$\triangle-$ Feminino $\quad-\circ-$ Masculino

Médias (robustas) das pregas adiposas de rapazes e raparigas do EMCV entre os 6 e os 10 anos.

\section{Perímetros Braquial e Geminal}

Os dois perímetros medidos neste estudo referem-se à massa muscular dos braços (PBRC) e pernas (PGML). Em ambos os casos rapazes e raparigas apresentam valores muito idênticos de massa muscular, e que aumentam regularmente ao longo do crescimento. Quando comparamos os valores de dispersão entre os mais e os menos musculados, constatamos que as diferenças entre ambos são estáveis ao longo do crescimento (ver diferenças entre valores percentílicos extremos nos quadros 8 e 9 . Comparativamente aos resultados encontrados na população lisboeta no perímetro braquial com contracção, as nossas crianças denotam menores valores de muscularidade $(p<.001)$ em todas as idades e sexos, mas o mesmo já não acontece relativamente às crianças madeirenses entre os 8-10 anos cujos valores são muito aproximados aos 


\begin{tabular}{|c|c|c|c|c|c|c|c|c|c|c|}
\hline \multirow[b]{2}{*}{ Idade } & \multicolumn{5}{|c|}{ Masculino } & \multicolumn{5}{|c|}{ Feminino } \\
\hline & 6 & 7 & 8 & 9 & 10 & 6 & 7 & 8 & 9 & 10 \\
\hline$N$ & 325 & 500 & 487 & 454 & 239 & 318 & 501 & 513 & 489 & 235 \\
\hline p95 & 17.5 & 17.6 & 19.0 & 21.3 & 23.0 & 19.0 & 21.0 & 21.5 & 23.5 & 24.0 \\
\hline p90 & 14.0 & 15.0 & 17.0 & 19.0 & 20.0 & 16.5 & 18.0 & 19.5 & 20.0 & 22.5 \\
\hline p75 & 10.0 & 11.0 & 12.5 & 13.5 & 15.5 & 13.0 & 14.0 & 15.5 & 16.0 & 17.0 \\
\hline p50 & 7.5 & 8.0 & 9.0 & 9.5 & 9.5 & 9.5 & 10.5 & 11.0 & 12.0 & 12.0 \\
\hline p25 & 6.5 & 6.5 & 7.0 & 7.0 & 7.0 & 7.5 & 8.0 & 8.0 & 9.0 & 9.0 \\
\hline p10 & 5.0 & 5.5 & 5.5 & 6.0 & 5.5 & 6.0 & 6.5 & 7.0 & 7.0 & 7.0 \\
\hline p05 & 5.0 & 5.0 & 5.0 & 5.0 & 5.0 & 6.0 & 6.0 & 6.0 & 6.2 & 6.5 \\
\hline$M$ & 8.7 & 9.4 & 10.2 & 11.0 & 11.5 & 10.8 & 11.4 & 12.3 & 13.0 & 13.6 \\
\hline M Hub & 7.8 & 8.5 & 9.2 & 9.9 & 10.2 & 10.0 & 10.7 & 11.5 & 12.3 & 12.7 \\
\hline DP & 3.6 & 4.1 & 4.7 & 5.2 & 5.9 & 4.3 & 4.5 & 5.1 & 5.1 & 5.8 \\
\hline Maia O० & $10.7^{* *}$ & $11.7^{\star *}$ & $13.4^{\star *}$ & $14.4^{\star *}$ & - & 13.9 ** & $14.0^{\star *}$ & $14.1^{\text {** }}$ & $16.7^{\text {** }}$ & - \\
\hline Lisboa 01 & $9.7^{\star *}$ & 9.9 & $11.1^{* *}$ & 11.8 & 11.5 & $11.9^{\star \star}$ & 11.7 & $13.1^{* *}$ & $14.3^{\star \star}$ & 13.9 \\
\hline Madeira 02 & - & - & 11.1 & 11.0 & 11.4 & - & - & 11.2 & 11.5 & 12.3 \\
\hline Portugal 02 & - & 11.2 & 11.9 ** & $13.3^{* *}$ & - & - & 13.6 ** & 14.7 * & $15.0^{* *}$ & - \\
\hline EUA 02 & $9.9^{* *}$ & $10.3^{*}$ & $12.3^{*}$ & $13.4^{*}$ & 14.0 ** & 11.1 & 11.5 & $14.3^{* *}$ & $15.4^{*}$ & $15.5^{\star \star}$ \\
\hline
\end{tabular}

\section{QUADRO4}

Valores percentílicos, média e desvio-padrão da SKTRI no EMCV e médias de outros estudos nacionais e internacionais.

${ }^{*} p<.05{ }^{* *} p<.001$ nossos. No perímetro geminal encontramos maiores valores nas crianças lisboetas $(p<.001$ para todas as idades com a excepção dos 10 anos masculinos], e resultados muito semelhantes nas raparigas madeirenses, mas inferiores nos rapazes $(p<.05$ aos 8 e 9 anos $)$.

\section{Diâmetros bicôndilo umeral e femural}

Os valores recolhidos nas crianças vianenses permitiram identificar diferenças importantes entre rapazes e raparigas nesta componente, com os rapazes a apresentarem larguras ósseas superiores aos seus pares do sexo feminino (cerca de $2 \mathrm{~mm}$ em média para o DBCU e $4 \mathrm{~mm}$ para o DBCF) em todas as idades.

Observando os valores extremos da distribuição percentílica (quadros 10 e 11) é fácil constatar que para todas as idades as diferenças entre os valores mínimos e máximos se mantiveram relativamente estáveis ao longo dos quatro anos. Comparativamente aos valores referenciados quer para a população infanto-juvenil lisboeta em 2001, quer para a norte-americana em 1994, as nossas crianças apresentam medidas de DBCU praticamente iguais. Já quanto ao DBCF as crianças vianenses apresentam valores muito semelhantes aos das lisboetas e ligeiramente superiores às madeirenses $(p<.001$ aos $9 \mathrm{e}$ 10 anos dos rapazes e aos 8 e 10 anos das raparigas].

\section{Somatótipo}

No quadro 12 e na figura 6 apresentamos as frequências (absolutas e relativas] dos somatótipos encontrados nos dois sexos para cada uma das idades e no seu

Valores percentílicos, média e desvio-padrão da SKGML no EMCV

e médias de outros estudos nacionais e internacionais.

* $\mathrm{p}<.05{ }^{* *} \mathrm{p}<.001$ 
total. A ordem de apresentação dos somatótipos obedece à sequência de localização na somatocarta (e portanto à sua contiguidade morfológical iniciando-se no meso-endomorfismo. Quando analisamos a configuração morfológica da totalidade das crianças durante este período etário verificamos que $68.5 \%$ do total dos rapazes se situam nas categorias em que o mesomorfismo é dominante, ou seja no espectro que vai desde os endo-mesomorfos (que são os mais frequentes com $20.5 \%$ ], aos mesomorfos-ectomorfos. Já nas raparigas é o endomorfismo que parece assumir o papel mais importante, com as meso-endomorfas [27.2\%], e as mesomorfas-endomorfas $[16 \%$ ) a constituírem no seu conjunto $43.2 \%$ do total da variação somatotipológica.

Olhando com mais atenção para as modificações ocorridas ao longo dos cinco anos (figura 6 e quadro 12) verifica-se uma tendência bipartida para um aumento dos associados com o ectomorfismo (mesomorfos-ectomorfos e meso-ectomorfos] bem como com o endomorfismo (meso-endomorfos), à custa da diminuição da percentagem de rapazes com predomínio do mesomorfismo lendo-mesomorfos, mesomorfos equilibrados, e ecto-mesomorfos].

No sexo feminino a predisposição parece ser principalmente para o aumento do endomorfismo (meso-endomorfas] com a idade e para a diminuição clara do mesomorfismo para valores muito baixos aos 10 anos (endo-mesomorfas, mesomorfas equilibradas, e ecto-mesomorfas]. Encontramos também, um aumento das raparigas classificadas como ectomorfas equilibradas.

\begin{tabular}{|c|c|c|c|c|c|c|c|c|c|c|}
\hline \multirow[b]{2}{*}{ Idade } & \multicolumn{5}{|c|}{ Masculino } & \multicolumn{5}{|c|}{ Feminino } \\
\hline & 6 & 7 & 8 & 9 & 10 & 6 & 7 & 8 & 9 & 10 \\
\hline$N$ & 325 & 500 & 487 & 454 & 239 & 317 & 501 & 512 & 488 & 235 \\
\hline p95 & 13.0 & 16.0 & 17.6 & 18.8 & 20.8 & 18.2 & 21.0 & 23.0 & 26.6 & 26.0 \\
\hline p90 & 10.0 & 11.7 & 13.5 & 15.0 & 18.0 & 15.0 & 16.5 & 19.0 & 18.6 & 21.0 \\
\hline p75 & 7.0 & 7.5 & 8.0 & 9.5 & 11.0 & 9.0 & 10.0 & 11.5 & 12.5 & 14.0 \\
\hline p50 & 5.5 & 6.0 & 6.0 & 6.0 & 6.5 & 6.5 & 7.0 & 7.0 & 7.5 & 8.0 \\
\hline p25 & 4.5 & 5.0 & 5.0 & 5.0 & 5.0 & 5.0 & 5.0 & 5.5 & 6.0 & 6.0 \\
\hline $\mathrm{p} 10$ & 4.0 & 4.0 & 4.0 & 4.0 & 4.0 & 4.5 & 4.5 & 4.5 & 5.0 & 5.0 \\
\hline p05 & 3.5 & 3.5 & 3.5 & 4.0 & 3.5 & 4.0 & 4.0 & 4.0 & 4.5 & 4.5 \\
\hline $\bar{M}$ & 6.4 & 7.1 & 7.7 & 8.3 & 8.8 & 8.3 & 8.8 & 9.5 & 10.4 & 11.1 \\
\hline M Hub & 5.5 & 5.8 & 6.2 & 6.5 & 6.7 & 6.7 & 7.2 & 7.5 & 8.4 & 8.6 \\
\hline $\mathrm{DP}$ & 3.7 & 4.5 & 4.9 & 5.4 & 6.0 & 5.1 & 5.5 & 6.0 & 6.8 & 7.7 \\
\hline Maia 00 & $7.4^{*}$ & $8.2^{*}$ & $9.6^{*}$ & $10.4^{*}$ & - & 9.1 & 9.7 & 9.7 & $12.2^{*}$ & - \\
\hline Lisboa 01 & $7.2^{*}$ & 7.5 & 8.2 & 9.0 & 8.5 & 8.7 & 8.9 & 10.0 & 11.3 & 11.5 \\
\hline Madeira 02 & - & - & 8.7 & 8.9 & 8.4 & - & - & 8.4 & 8.5 & 9.5 \\
\hline Portugal 02 & - & 7.4 & 8.6 ** & $9.6 * \star$ & - & - & $13.6^{* *}$ & $14.7^{*}$ & $15.0^{* *}$ & - \\
\hline EUA 02 & 6.6 & 7.0 & $8.9 *$ & 8.5 & 10.3 & 7.6 & 7.7 * & 10.4 & 10.8 & 11.9 \\
\hline
\end{tabular}

QUADRO6

Valores percentílicos, média e desvio-padrão da SKSBS no EMCV e médias de outros estudos nacionais e internacionais.

* $p<.05 * * p<.001$

\begin{tabular}{|c|c|c|c|c|c|c|c|c|c|c|}
\hline \multirow[b]{2}{*}{ Idade } & \multicolumn{5}{|c|}{ Masculino } & \multicolumn{5}{|c|}{ Feminino } \\
\hline & 6 & 7 & 8 & 9 & 10 & 6 & 7 & 8 & 9 & 10 \\
\hline$N$ & 325 & 502 & 486 & 453 & 239 & 317 & 501 & 510 & 489 & 235 \\
\hline p95 & 17.0 & 18.6 & 21.6 & 23.0 & 28.0 & 20.2 & 21.6 & 22.0 & 25.0 & 26.0 \\
\hline p90 & 11.0 & 13.0 & 16.6 & 19.0 & 22.7 & 15.0 & 17.7 & 19.0 & 22.0 & 23.0 \\
\hline p75 & 6.5 & 7.0 & 9.0 & 11.0 & 14.0 & 9.4 & 11.0 & 12.5 & 15.0 & 15.0 \\
\hline p50 & 4.0 & 4.5 & 5.0 & 5.9 & 5.5 & 5.5 & 6.0 & 6.5 & 8.0 & 8.0 \\
\hline p25 & 3.0 & 3.5 & 4.0 & 4.0 & 3.5 & 4.0 & 4.0 & 4.5 & 5.0 & 5.0 \\
\hline $\mathrm{p} 10$ & 2.5 & 3.0 & 3.0 & 3.0 & 3.0 & 3.0 & 3.5 & 3.5 & 3.5 & 3.5 \\
\hline p05 & 2.5 & 2.5 & 2.5 & 3.0 & 3.0 & 3.0 & 3.0 & 3.0 & 3.0 & 3.0 \\
\hline$M$ & 5.8 & 6.6 & 7.7 & 8.6 & 9.8 & 7.6 & 8.6 & 9.4 & 10.6 & 11.2 \\
\hline M Hub & 4.3 & 5.0 & 5.7 & 6.3 & 6.3 & 5.9 & 6.7 & 7.3 & 8.9 & 9.1 \\
\hline DP & 4.8 & 5.2 & 6.3 & 6.9 & 8.7 & 5.4 & 6.2 & 6.5 & 7.1 & 8.1 \\
\hline Maia O० & $9.0^{* *}$ & $10.7^{\text {** }}$ & 13.9 ** & $15.1^{\star \star}$ & - & $12.8^{\star \star}$ & 13.1 ** & 13.1 ** & $18.3^{\star \star}$ & - \\
\hline Lisboa 01 & 6.6 & $7.8^{\star \star}$ & 8.3 & $9.9 *$ & 9.1 & $9.2^{\star \star}$ & $9.5^{*}$ & $10.3^{*}$ & $11.9^{*}$ & 12.0 \\
\hline Madeira 02 & - & - & 8.7 & 9.9 & 9.8 & - & - & 9.9 & 10.1 & 12.0 \\
\hline EUA 94 & 6.9 & 7.6 & 8.5 & $10.8^{*}$ & 11.7 & 7.6 & 9.8 & 9.7 & 12.7 * & 13.5 \\
\hline
\end{tabular}

QUADRO7

Valores percentílicos, média e desvio-padrão da SKSIL no EMCV e médias de outros estudos nacionais e internacionais.

${ }^{*} p<.05{ }^{* *} p<.001$ 

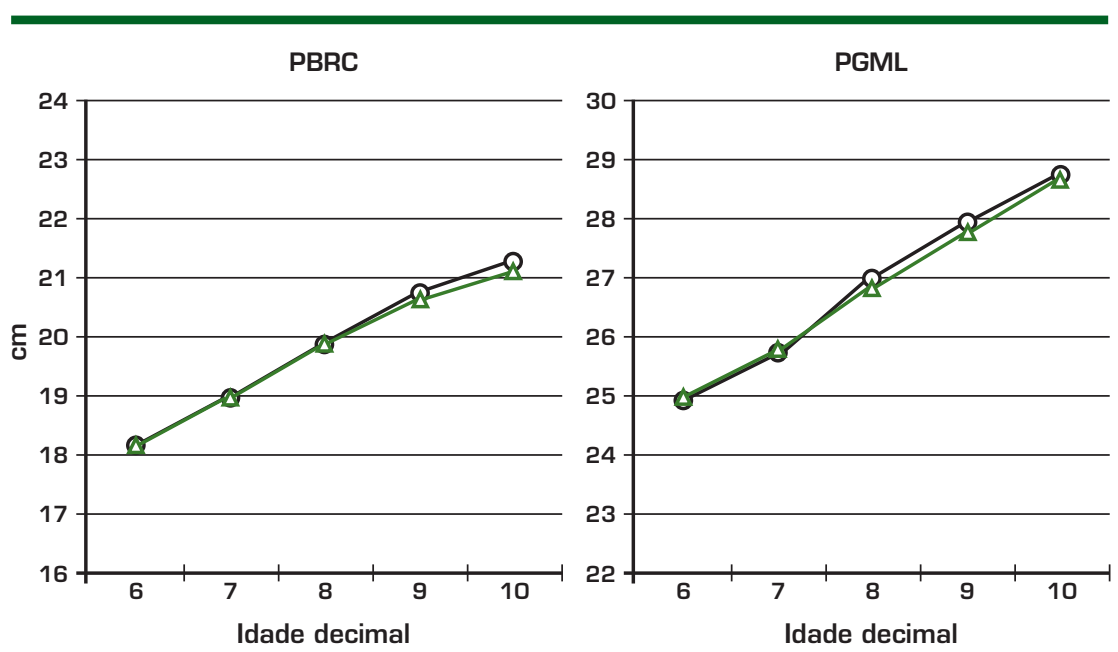

FIGURA4 Médias dos perímetros branquial com contracção e geminal de rapazes e raparigas do EMCV entre os 6 e os 10 anos.

LEGENDA

$\triangle-$ Feminino $\quad-\circ-$ Masculino

\section{DISCUSSÃO}

Rapazes e raparigas vianenses apresentam valores muito semeIhantes na sua estatura, peso, e perimetros entre os 6 e os 10 anos de idade, no entanto estas semelhanças mascaram diferenças

fundamentais quanto às características morfológicas associadas ao género e que são notórias ao longo de todos os escalões etários. Os rapazes possuem sempre superioridade nas dimensões esqueléticas

\begin{tabular}{|c|c|c|c|c|c|c|c|c|c|c|}
\hline \multirow[b]{2}{*}{ Idade } & \multicolumn{5}{|c|}{ Masculino } & \multicolumn{5}{|c|}{ Feminino } \\
\hline & 6 & 7 & 8 & 9 & 10 & 6 & 7 & 8 & 9 & 10 \\
\hline$N$ & 324 & 499 & 487 & 454 & 239 & 318 & 500 & 513 & 489 & 234 \\
\hline p95 & 22.1 & 22.9 & 24.3 & 25.3 & 26.3 & 21.5 & 22.8 & 23.7 & 25.1 & 25.9 \\
\hline p90 & 20.8 & 21.9 & 23.1 & 24.1 & 25.4 & 21.0 & 21.9 & 22.9 & 23.8 & 24.9 \\
\hline p75 & 19.1 & 20.1 & 21.1 & 22.3 & 23.4 & 19.5 & 20.1 & 21.0 & 22.2 & 22.8 \\
\hline p50 & 17.9 & 18.6 & 19.5 & 20.4 & 20.8 & 17.9 & 18.7 & 19.5 & 20.4 & 20.8 \\
\hline p25 & 16.9 & 17.5 & 18.4 & 19.0 & 19.5 & 16.7 & 17.5 & 18.3 & 19.1 & 19.5 \\
\hline p10 & 16.0 & 16.7 & 17.4 & 18.0 & 18.5 & 16.0 & 16.5 & 17.3 & 17.9 & 18.3 \\
\hline p05 & 15.6 & 16.1 & 16.7 & 17.6 & 18.2 & 15.4 & 16.0 & 16.6 & 17.3 & 17.7 \\
\hline$M$ & 18.2 & 19.0 & 19.9 & 20.8 & 21.4 & 18.2 & 19.0 & 19.9 & 20.7 & 21.2 \\
\hline DP & 1.9 & 2.1 & 2.3 & 2.4 & 2.7 & 2.0 & 2.0 & 2.2 & 2.3 & 2.5 \\
\hline Lisboa 01 & $19.4^{* *}$ & $20.4^{\star \star}$ & $21.4^{\star *}$ & $22.2^{* *}$ & 22.4 ** & 20.0 ** & $20.4^{* *}$ & $21.5^{\star \star}$ & $22.8^{\star \star}$ & 22.9 ** \\
\hline Madeira 02 & - & - & 20.1 & 20.6 & 21.5 & - & - & 20.2 & 21.0 & 21.2 \\
\hline
\end{tabular}

\section{QUADRO8}

Valores percentílicos, média e desvio-padrão da PRBC no EMCV

e médias de outros estudos nacionais e internacionais.

${ }^{*} p<.05{ }^{* *} p<.001$ (diâmetros) e as raparigas na adiposidade corporal, o que se reflecte no dimorfismo configuracional que confere ao sexo masculino ljá desde o período infanto-juvenil] melhores condições de aptidão morfológica para o movimento. Isto mesmo é possível verificar aquando da análise dos somatótipos exibidos em cada idade e das transformações sentidas na passagem para a pré-puberdade e puberdade, com diferenças evidentes nos padrões somatotipológicos dominantes aos 10 anos de idade. Nos rapazes encontram-se duas tendências opostas: por um lado aumentam os perfis associados ao endomorfismo enquanto no outro extremo se acentuam as configurações morfológicas usualmente identificadas como mais aptas (meso-ectomorfismo). Nas raparigas a maior predominância encontra-se no aumento do endomorfismo associado ao decréscimo da influência do mesomorfismo, o que as parece afastar mais dos parâmetros morfológicos usualmente associados com a aptidão motora.

Relativamente aos indicadores morfológicos simples, e comparativamente a outras populações nacionais e internacionais da mesma faixa etária, as crianças vianenses demonstraram possuir: (1) estatura média ligeiramente superior às reportadas nos estudos portugueses e um ritmo de crescimento diferente das norte-americanas, sendo mais altos aos 6 anos mas mais baixos aos 10 anos; (2) peso semelhante ao dos congéneres nacionais mas inferior ao das crianças dos EUA; (3) valores de pregas adiposas inferiores ou da mesma magnitude aos reportados para Portugal; (4) perímetros musculares e diâmetros ósseos semelhantes aos seus pares portugueses. 
Específicamente quanto aos valores de adiposidade, e porque eles constituem uma preocupação cada vez mais premente no mundo moderno, e apesar de não existir um valor de referência para classificar as pregas adiposas, podemos considerar que os valores apresentados pelas crianças vianenses posicionadas no percentil 50 são relativamente baixos. No entanto o mesmo não pode ser dito das crianças cujos valores se situam acima deste percentil, já que nestes casos os registos são muito mais elevados e ainda por cima aumentam bastante de ano para ano, característica que faz denotar a extrema assimetria entre os valores de adiposidade nesta população. Enquanto cerca de metade das crianças (abaixo do $p 50$ ) possuem valores baixos e muito aproximados de massa gorda subcutânea (ver valores percentílicos nos quadros 4 a 7) a metade superior ao $p 50$ revela um grande distanciamento da mediana e uma grande dispersão dos valores. Especial preocupação deve pois incidir sobre as crianças que se situam acima do $p 75$, visto que após os 8 anos apresentam já pregas adiposas de grande dimensão.

Quanto às características somatotipológicas constatamos que, no 1 - CEB em Viana do Castelo, o mesomorfismo é a componente mais evidenciada pelos rapazes e o endomorfismo pelas raparigas. No entanto, e ao longo da idade, as modificações vão ocorrendo no sentido de as raparigas se tornarem mais mesomorfas, enquanto os rapazes parecem caminhar em dois sentidos opostos; aumentam os perfis associados ao endomorfismo, mas também os ecto-mesomorfos geralmente associados a melhor aptidão motora. $A$ inexis-
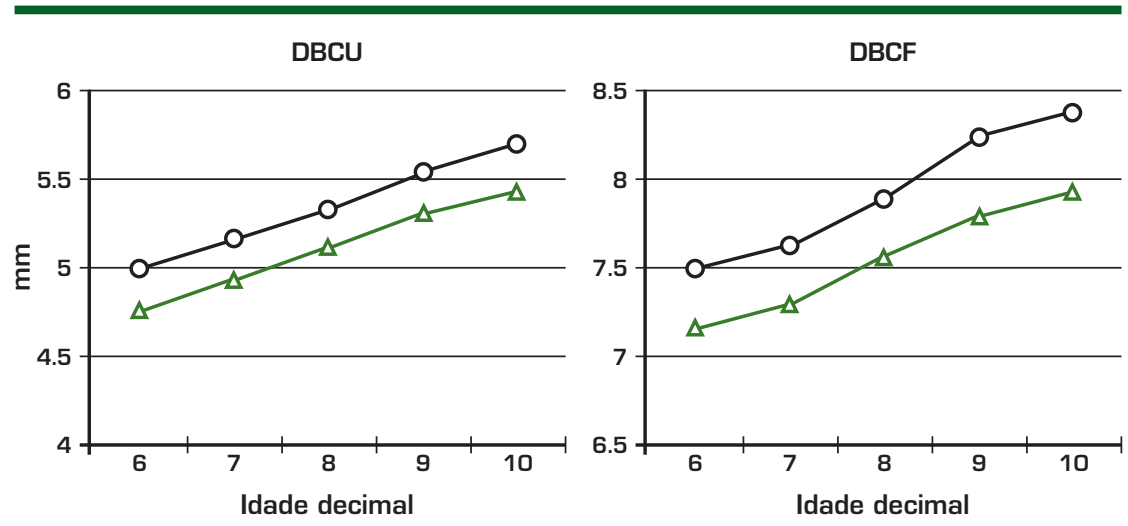

LEGENDA

FIGURA5 $\triangle$ Feminino $-\mathrm{-}$ - Masculino

Médias dos diâmetros bicôndilo umeral e femural de rapazes e raparigas do EMCV entre os 6 e os 10 anos.

tência de estudos nacionais que refiram este tipo de abordagem com crianças destas idades, e o facto de os escassos estudos internacionais apresentarem os seus resultados sob a forma do somatótipo médio e não das frequências, dificulta a nossa comparação. Apesar destas limitações, este comportamento assemelha-se de uma forma geral ao modelo empírico descrito por Carter e Heath $^{5}$ e observado em rapazes canadianos $^{6}$, e rapazes e raparigas belgas. Em ambos os casos é descrito que neste período etário os rapazes tendem a decrescer em mesomorfismo e a aumentar em ectomorfismo, enquanto as raparigas diminuem no mesomorfismo e aumentam a componente endomorfa.

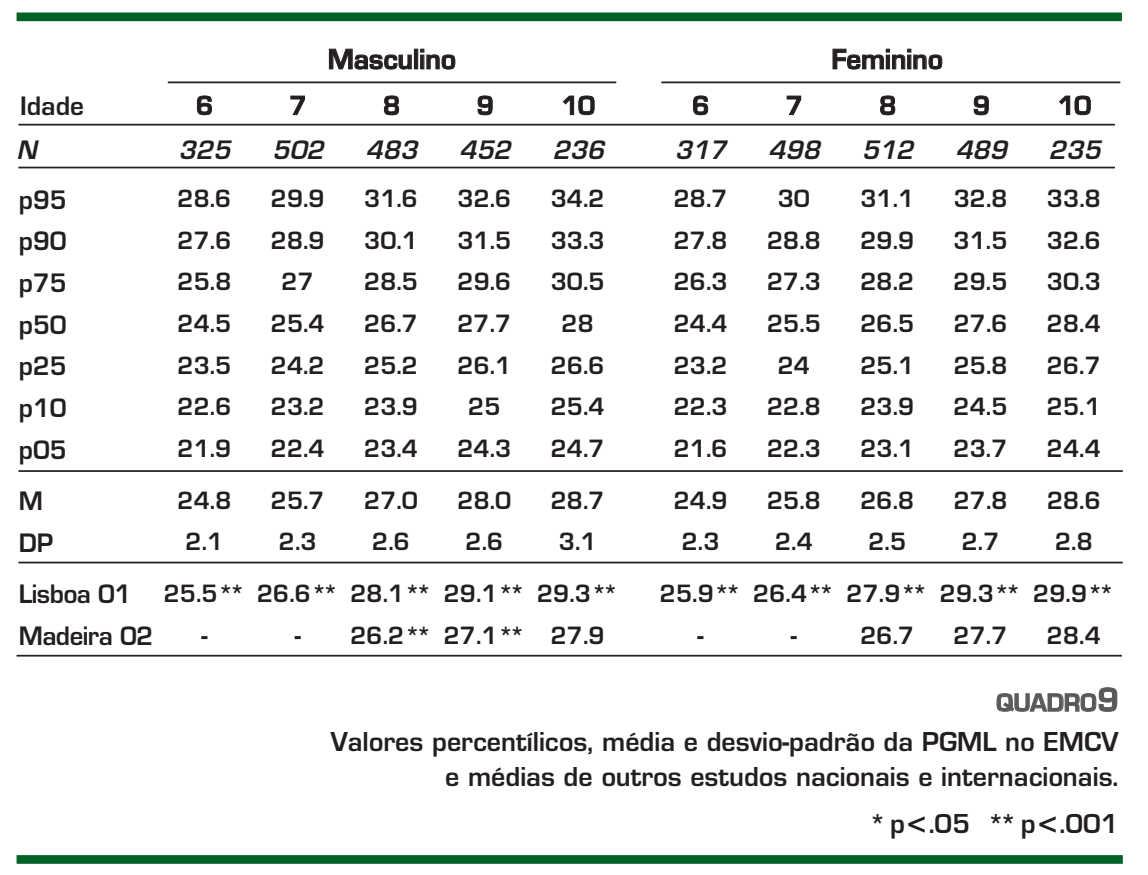




\begin{tabular}{|c|c|c|c|c|c|c|c|c|c|c|}
\hline \multirow[b]{2}{*}{ Idade } & \multicolumn{5}{|c|}{ Masculino } & \multicolumn{5}{|c|}{ Feminino } \\
\hline & 6 & 7 & 8 & 9 & 10 & 6 & 7 & 8 & 9 & 10 \\
\hline$N$ & 324 & 501 & 485 & 454 & 239 & 315 & 501 & 514 & 489 & 235 \\
\hline p95 & 5.5 & 5.7 & 5.9 & 6.1 & 5.5 & 5.3 & 5.5 & 5.7 & 5.9 & 5.3 \\
\hline p90 & 5.4 & 5.6 & 5.7 & 6.0 & 5.4 & 5.2 & 5.3 & 5.6 & 5.8 & 5.2 \\
\hline p75 & 5.2 & 5.3 & 5.6 & 5.8 & 5.2 & 5.0 & 5.1 & 5.3 & 5.6 & 5.0 \\
\hline p50 & 5.0 & 5.1 & 5.4 & 5.5 & 5.0 & 4.8 & 4.9 & 5.1 & 5.3 & 4.8 \\
\hline p25 & 4.8 & 4.9 & 5.1 & 5.3 & 4.8 & 4.6 & 4.7 & 4.9 & 5.1 & 4.6 \\
\hline p10 & 4.6 & 4.7 & 4.9 & 5.2 & 4.6 & 4.4 & 4.6 & 4.7 & 4.9 & 4.4 \\
\hline p05 & 4.5 & 4.6 & 4.8 & 5.0 & 4.5 & 4.3 & 4.5 & 4.6 & 4.9 & 4.3 \\
\hline $\bar{M}$ & 5.0 & 5.1 & 5.4 & 5.5 & 5.7 & 4.8 & 4.9 & 5.1 & 5.3 & 5.5 \\
\hline DP & 0.3 & 0.3 & 0.3 & 0.3 & 0.4 & 0.3 & 0.3 & 0.3 & 0.3 & 0.4 \\
\hline Lisboa 01 & 4.8 & 5.1 & 5.3 & 5.4 & 5.5 & 4.6 & 4.9 & 5.0 & 5.3 & 5.4 \\
\hline Madeira 02 & - & - & 5.3 & 5.4 & 5.5 & - & - & 5.0 & 5.1 & 5.2 \\
\hline EUA 94 & 5.1 & 5.3 & 5.6 & 5.8 & 5.9 & 4.9 & 5.1 & 5.3 & 5.6 & 5.7 \\
\hline
\end{tabular}

\section{QUADR010}

Valores percentílicos, média e desvio-padrão da DBCU no EMCV

e médias de outros estudos nacionais e internacionais.

${ }^{*} p<.05{ }^{* *} p<.001$
O panorama encontrado no EMCV parece indicar que a morfologia das crianças vianenses ao longo do crescimento não inspira ainda cuidado, encontrando-se dentro de parâmetros favoráveis ao desenvolvimento da aptidão morfológica.
As preocupantes mudanças morfológicas já amplamente documentadas nas populações internacionais ${ }^{7}$, e que se parecem começar a identificar já nas população da capital portuguesa, ainda não se fizeram sentir em Viana do Castelo. Por

\begin{tabular}{|c|c|c|c|c|c|c|c|c|c|c|}
\hline \multirow[b]{2}{*}{ Idade } & \multicolumn{5}{|c|}{ Masculino } & \multicolumn{5}{|c|}{ Feminino } \\
\hline & 6 & 7 & 8 & 9 & 10 & 6 & 7 & 8 & 9 & 10 \\
\hline$N$ & 322 & 501 & 486 & 454 & 239 & 318 & 500 & 510 & 489 & 235 \\
\hline p95 & 8.2 & 8.3 & 8.6 & 9.0 & 9.3 & 7.8 & 8.0 & 8.4 & 8.6 & 8.8 \\
\hline p90 & 8.0 & 8.2 & 8.5 & 8.8 & 9.0 & 7.7 & 7.8 & 8.1 & 8.4 & 8.6 \\
\hline p75 & 7.7 & 8.0 & 8.2 & 8.5 & 8.7 & 7.4 & 7.6 & 7.8 & 8.1 & 8.3 \\
\hline p50 & 7.5 & 7.7 & 7.9 & 8.2 & 8.3 & 7.1 & 7.3 & 7.5 & 7.8 & 7.9 \\
\hline p25 & 7.2 & 7.4 & 7.6 & 7.9 & 8.0 & 6.8 & 7.0 & 7.2 & 7.5 & 7.6 \\
\hline $\mathrm{p} 10$ & 7.0 & 7.2 & 7.3 & 7.6 & 7.8 & 6.6 & 6.8 & 7.0 & 7.2 & 7.4 \\
\hline p05 & 6.9 & 7.0 & 7.2 & 7.5 & 7.6 & 6.5 & 6.7 & 6.9 & 7.1 & 7.2 \\
\hline$M$ & 7.5 & 7.7 & 7.9 & 8.2 & 8.4 & 7.1 & 7.3 & 7.6 & 7.8 & 8.0 \\
\hline DP & 0.4 & 0.4 & 0.4 & 0.4 & 0.5 & 0.4 & 0.4 & 0.4 & 0.5 & 0.5 \\
\hline Lisboa 01 & $7.4^{\star}$ & 7.7 & 7.9 & $8.1^{\star *}$ & $8.2^{\star \star}$ & $7.0^{*}$ & 7.3 & $7.5^{\star \star}$ & 7.8 & 7.9 \\
\hline Madeira 02 & - & - & 7.8 & $8.0 * *$ & 8.1 ** & - & - & $7.3^{* \star}$ & 7.7 & $7.8^{\star *}$ \\
\hline
\end{tabular}

\section{QUADR011}

Valores percentílicos, média e desvio-padrão da DBCF no EMCV

e médias de outros estudos nacionais e internacionais.

${ }^{*} p<.05{ }^{* *} p<.001$ outro lado o crescimento secular em altura da nossa população foi evidente, recuperando do atraso reportado em 1981 para igualar ou ultrapassar hoje a média nacional, facto que constitui indicador importante do desenvolvimento da população infanto-juvenil vianense nos últimos trinta anos.

Apesar de tudo e porque as interpretações médias tendem a minimizar os acontecimentos extremos ou as tendências divergentes, é necessário identificar desde cedo as crianças que parecem mostrar tendência para uma menor aptidão morfológica. Esperamos que os resultados que agora compartiIhamos com a comunidade académica, educativa e clínica possam ajudar a essa detecção, bem como a uma maior preocupação de todos na avaliação destes indicadores fundamentais do desenvolvimento das nossas crianças e jovens.

\section{AGRADECIMENTOS}

Os autores querem expressar os seus mais profundos agradecimentos à Câmara Municipal de Viana do Castelo pelo apoio prestado ao EMCV, às escolas do 1을 $\mathrm{e}$ respectivos professores e alunos pela sua colaboração desinteressada, e aos alunos finalistas do Curso de Educação Física que constituíram a equipa de observação e sem os quais este estudo teria sido impossivel de concretizar. Um especial agradecimento é devido às Doutoras Filomena Vieira e Isabel Fragoso pelas valiosas correcções e sugestões relativas à publicação dos resultados do EMCV, e pela disponibilização dos resultados relativos ao estudo Reavaliação antropométrica da população infantil de Lisboa, quando este ainda se encontrava no prelo. 


\begin{tabular}{|c|c|c|c|c|c|c|c|c|c|c|c|c|c|}
\hline & & \multicolumn{5}{|c|}{ MASCULINO } & \multicolumn{5}{|c|}{ FEMININO } & \multicolumn{2}{|c|}{ TOTAL } \\
\hline & & 6 & 7 & 8 & 9 & 10 & 6 & 7 & 8 & 9 & 10 & Masculino & Masculino \\
\hline Meso & $\mathrm{n}$ & 18 & 40 & 58 & 70 & 43 & 56 & 121 & 138 & 153 & 84 & 229 & 552 \\
\hline Endomorfo & $\%$ & $5.6 \%$ & $8.1 \%$ & $12.1 \%$ & $15.5 \%$ & $18.2 \%$ & $17.9 \%$ & $24.4 \%$ & $27.5 \%$ & $31.4 \%$ & $36.2 \%$ & $11.5 \%$ & $27.2 \%$ \\
\hline \multirow{2}{*}{$\begin{array}{l}\text { Mesomorfo } \\
\text { Endomorfo }\end{array}$} & $n$ & 15 & 47 & 55 & 50 & 29 & 60 & 91 & 75 & 76 & 23 & 196 & 325 \\
\hline & $\%$ & $4.7 \%$ & $9.5 \%$ & $11.5 \%$ & $11.1 \%$ & $12.3 \%$ & $19.2 \%$ & $18.3 \%$ & $14.9 \%$ & $15.6 \%$ & $9.9 \%$ & $9.9 \%$ & $16.0 \%$ \\
\hline \multirow{2}{*}{$\begin{array}{l}\text { Endo } \\
\text { Mesomorfo }\end{array}$} & $\mathrm{n}$ & 101 & 125 & 87 & 74 & 19 & 71 & 71 & 49 & 26 & 10 & 406 & 227 \\
\hline & $\%$ & $31.5 \%$ & $25.2 \%$ & $18.2 \%$ & $16.4 \%$ & $8.1 \%$ & $22.7 \%$ & $14.3 \%$ & $9.8 \%$ & $5.3 \%$ & $4.3 \%$ & $20.5 \%$ & $11.2 \%$ \\
\hline \multirow{2}{*}{$\begin{array}{l}\text { Mesomorfo } \\
\text { Equilibrado }\end{array}$} & $\mathrm{n}$ & 78 & 105 & 85 & 56 & 27 & 57 & 57 & 50 & 41 & 16 & 351 & 221 \\
\hline & $\%$ & $24.3 \%$ & $21.2 \%$ & $17.7 \%$ & $12.4 \%$ & $11.4 \%$ & $18.2 \%$ & $11.5 \%$ & $10.0 \%$ & $8.4 \%$ & $6.9 \%$ & $17.7 \%$ & $10.9 \%$ \\
\hline \multirow{2}{*}{$\begin{array}{l}\text { Ecto } \\
\text { Mesomorfo } \\
\end{array}$} & $\mathrm{n}$ & 66 & 76 & 76 & 56 & 24 & 20 & 35 & 18 & 6 & 2 & 298 & 81 \\
\hline & $\%$ & $20.6 \%$ & $15.3 \%$ & $15.9 \%$ & $12.4 \%$ & $10.2 \%$ & $6.4 \%$ & $7.1 \%$ & $3.6 \%$ & $1.2 \%$ & $.9 \%$ & $15.0 \%$ & $4.0 \%$ \\
\hline \multirow{2}{*}{$\begin{array}{l}\text { Mesomorfo } \\
\text { Ectomorfo }\end{array}$} & $\mathrm{n}$ & 27 & 71 & 76 & 83 & 47 & 25 & 47 & 47 & 46 & 23 & 304 & 188 \\
\hline & $\%$ & $8.4 \%$ & $14.3 \%$ & $15.9 \%$ & $18.4 \%$ & $19.9 \%$ & $8.0 \%$ & $9.5 \%$ & $9.4 \%$ & $9.4 \%$ & $9.9 \%$ & $15.3 \%$ & $9.3 \%$ \\
\hline \multirow{2}{*}{$\begin{array}{l}\text { Meso } \\
\text { Ectomorfo }\end{array}$} & $\mathrm{n}$ & 11 & 23 & 36 & 48 & 38 & 10 & 30 & 49 & 47 & 24 & 156 & 160 \\
\hline & $\%$ & $3.4 \%$ & $4.6 \%$ & $7.5 \%$ & $10.6 \%$ & $16.1 \%$ & $3.2 \%$ & $6.0 \%$ & $9.8 \%$ & $9.6 \%$ & $10.3 \%$ & $7.9 \%$ & $7.9 \%$ \\
\hline \multirow{2}{*}{$\begin{array}{l}\text { Ectomorfo } \\
\text { Equilibrado }\end{array}$} & $\mathrm{n}$ & - & 2 & 1 & 2 & 4 & 4 & 6 & 21 & 28 & 20 & 9 & 79 \\
\hline & $\%$ & - & $.4 \%$ & $.2 \%$ & $.4 \%$ & $1.7 \%$ & $1.3 \%$ & $1.2 \%$ & $4.2 \%$ & $5.7 \%$ & $8.6 \%$ & $.5 \%$ & $3.9 \%$ \\
\hline \multirow{2}{*}{$\begin{array}{l}\text { Endo } \\
\text { Ectomorfo }\end{array}$} & $\mathrm{n}$ & - & - & - & - & - & - & - & 1 & - & - & - & 1 \\
\hline & $\%$ & - & - & - & - & - & - & - & $.2 \%$ & - & - & - & $.0 \%$ \\
\hline \multirow{2}{*}{$\begin{array}{l}\text { Endomorfo } \\
\text { Ectomorfo } \\
\end{array}$} & $\mathrm{n}$ & - & - & - & 1 & - & - & 1 & 6 & 7 & 4 & 1 & 18 \\
\hline & $\%$ & - & - & - & $.2 \%$ & - & - & $.2 \%$ & $1.2 \%$ & $1.4 \%$ & $1.7 \%$ & $.1 \%$ & $.9 \%$ \\
\hline \multirow{2}{*}{$\begin{array}{l}\text { Ecto } \\
\text { Endomorfo }\end{array}$} & $\mathrm{n}$ & - & - & - & - & - & - & - & - & 1 & - & - & 1 \\
\hline & $\%$ & - & - & - & - & - & - & - & - & $.2 \%$ & - & - & $.0 \%$ \\
\hline \multirow{2}{*}{$\begin{array}{l}\text { Endomorfo } \\
\text { Equilibrado }\end{array}$} & $\mathrm{n}$ & - & - & - & - & 1 & - & 5 & 9 & 19 & 9 & 1 & 42 \\
\hline & $\%$ & - & - & - & - & $.4 \%$ & - & $1.0 \%$ & $1.8 \%$ & $3.9 \%$ & $3.9 \%$ & $.1 \%$ & $2.1 \%$ \\
\hline \multirow{2}{*}{ Central } & $\mathrm{n}$ & 5 & 7 & 5 & 11 & 4 & 10 & 32 & 39 & 38 & 17 & 32 & 136 \\
\hline & $\%$ & $1.6 \%$ & $1.4 \%$ & $1.0 \%$ & $2.4 \%$ & $1.7 \%$ & $3.2 \%$ & $6.5 \%$ & $7.8 \%$ & $7.8 \%$ & $7.3 \%$ & $1.6 \%$ & $6.7 \%$ \\
\hline TOTAIS & $\mathrm{n}$ & 321 & 496 & 479 & 451 & 236 & 313 & 496 & 502 & 488 & 232 & 1983 & 2031 \\
\hline
\end{tabular}

QUADR012

\section{CORRESPONDÊNCIA}

Luís Paulo Rodrigues

Escola Superior Educação

Viana do Castelo

Av. Capitão Gaspar de Castro

- Apartado 513

4901-908 Viana do Castelo

Telf.: 258806200

Fax: 258806209

E-mail: Iprodrigues@ese.jpvc.pt

\section{REFERÊNCIAS}

1. Bell W (1993). Body size and shape: a longitudinal investigation of active and sedentary boys during adolescence. Journal Sports Sciences, 11, 127-138.

2. Boennec P, Prevot M, Ginet S (1980). Somatotype du sportif de haut niveau. Resultats dans huit disciplines differents. Medicine du Sport, 54 309-318.
3. Carter JEL (1970). The somatotypes of athletes - a review. Human Biology, 42, 535-569

4. Carter JEL (1988). Somatotypes of children in sports. In R. Malina (Ed), Young athletes. Biological, psycological and educational perspectives (pp 153-165). Champaign: Human Kinetics.

5. Carter JEL, Heath BH (1990). Somatotyping. Development and 

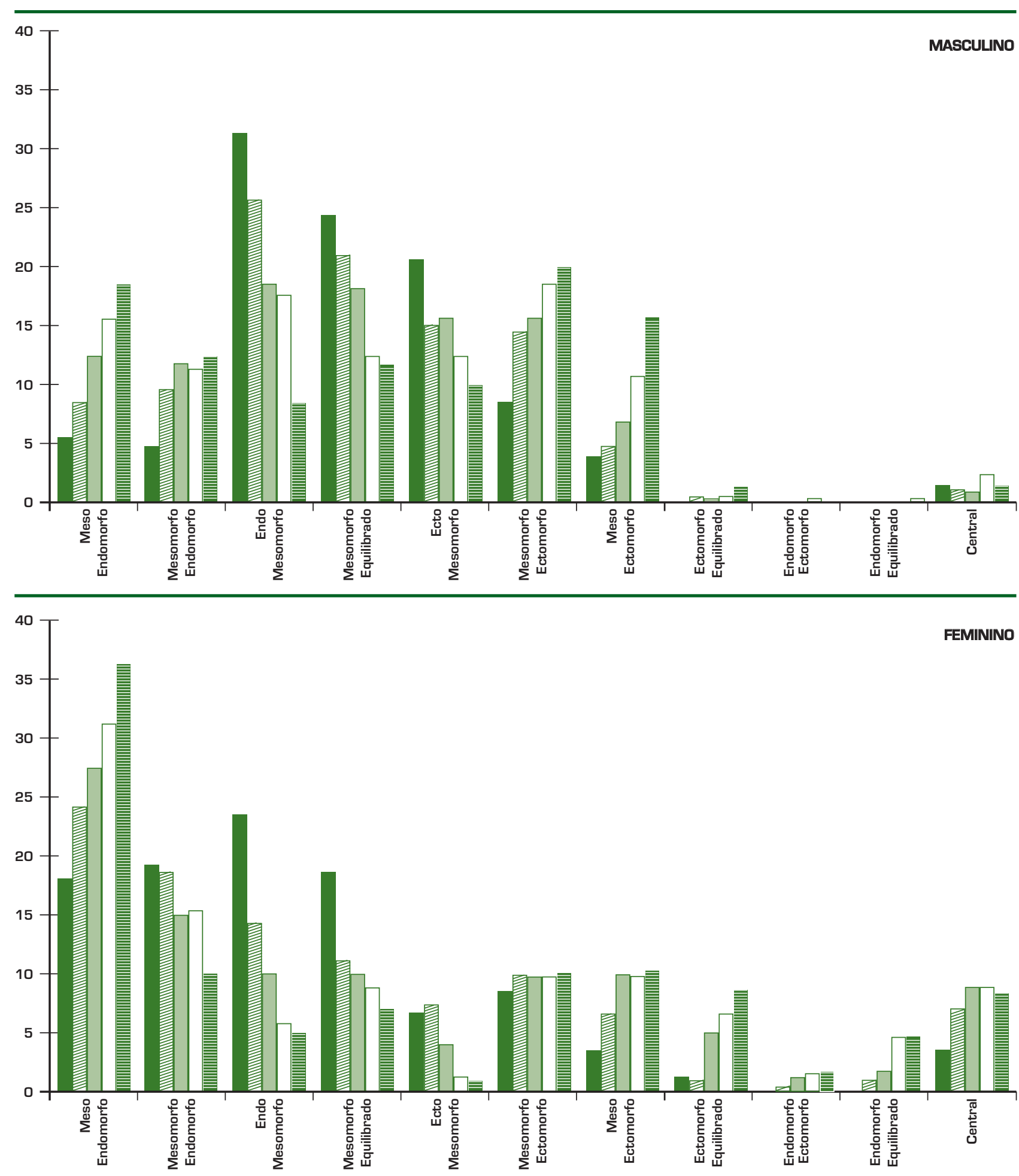
applications. Cambridge: Cambridge University Press.

6. Carter JEL, Mirwald RL, Heath-Roll BH, Bayley DA (1977). Somatotypes of 7- to 16-year-old boys in Saskatchewan, Canada. Am. J. Hum. Biol. 9: 257-272.

7. Cole TJ, Bellizzi MC, Flegal KM, Dietz WH (2000). Establishing a standard definition for child overweight and obesity worldwide: international survey. BMJ 320 (7244), 1240-1243.

8. Hauspie R (2002). Flemish Growth Curves. Retrieved June 192006 from

http://homepages.vub.ac.be/ rha uspie/CurrentRes.html

9. Freitas D, Maia J, Beunen G, Lefevre J, Claesens A, Marques A, Rodrigues A, Silva C e Crespo M (2002). Crescimento somático, maturação biológica, aptidão física e estatuto sócio-económico de crianças e adolescentes madejrenses. $O$ estudo de crescimento da Madeira. Funchal: Universidade da Madeira.

10. Frisancho A (1990). Anthropometric standards for the assessment of growth and nutritional status. Michigan: The University of Michigan Press.

11. Hebbelinck M, Duquet W, Borms J, Carter JEL (1995). Stability of somatotypes: A longitudinal study of Belgian children age 6 to 17 years. Am. J. Hum. Biol. 7:575-588.

12. Holopainen S, Hakkinen P, Telama R (1984). Level and rate of development of motor fitness, motor abilities and skills by somatotype. Scandinavian Journal Sports Science, 6, 67-75.

13. INE (2003). Retrato territorial por NUTS e Concelhos. Retrieved July 13, 2004 from http://www.ine.pt/prodserv/retr ato/retrato.asp

14. Maia J, Lopes V, Campos M, Silva R, Seabra A, Morais F, Fonseca A, Freitas D e Prista A. (2006). Crescimento, desenvolvimento e saúde. Três anos de estudo com crianças e jovens açorianos. Açores: DREFD, DRCT e FCDEF-UP.

15. Maia J, Lopes V, Morais F, Silva R, Seabra A. (2002). Estudo do crescimento somático, aptidão física e capacidade de coordenação corporal de crianças do $1 \stackrel{\circ}{\circ}$ Ciclo do Ensino Básico da Região Autónoma dos Açores. Açores: DREFD, DRCT e FCDEF-UP.

16. Maia J, Lopes V, Silva R, Seabra A, Morais F, Fonseca A, Cardoso M, Prista A, Feitas D (2003). Um olhar sobre crianças e jovens da Região Autonóma dos Açores Implicações para a educação física, desporto e Saúde. Açores: DREFD, DRCT e FCDEF-UP.

17. McDowell MA, Fryar CD, Hirsch R, Ogden CL. (2005). Anthropometric reference data for children and adults: U.S. population, 19992002. Advance data from vital and health statistics; 361. Hyattsville, MD: National Center for Health Statistics.

18. CDC (2004). National Health and Nutrition Examination Survey http://www.cdc.gov/nchs/about/ /major/nhanes/nhanes2003-2004/nhanes03_04.htm

19. Department of Health (2004). Health Survey for England. Retrieved June 192006 from

http://www.dh.gov.uk/Publication sAndStatistics/PublishedSurvey/ /HealthSurveyForEngland/fs/en

20. Ogden CL, Fryar CD, Carroll MD, Flegal KM (2004). Mean body weight, height, and body mass index, United States 1960-2002. Advance data from vital and health statistics; no 347. Hyattsville, Maryland: National Center for Health Statistics.

21. Lohman TG, Roche AF, Martorell $\mathrm{R}$, eds. 1988. Anthropometric Standardization Reference Manual. Abridged edition. Champaign, IL: Human Kinetics Books.

22. Pariskova J, Carter JEL (1976). Influence of physical activity on stability of somatotypes in boys. American Journal of Physical Anth-ropology. 44, 327340.

23. Padez C, Mourão TFI, Moreira P, Rosado V (2004). Prevalence of overweight and obesity in 7-9-yearold Portuguese children: Trends in body mass index from 19702002. American Journal of Human Biology 16(6): 670-678.

24. Pereira A (2000). Crescimento somático e aptidão física de criancas com idades compreendidas entre os seis e os dez anos de idade. Um estudo no concelho da Maia. Tese de Mestrado. FCDEF-UP: Porto.

25. Rosa R (1983). Estudos sobre o desenvolvimento da criança portuguesa em idade escolar. Min. Educação e IASE: Lisboa.

26. Shrout P, Fleiss J (1979). Intraclass correlations: Uses in assessing rater reliability. Psychological Bulletin, 86 (2): 420-428.

27. Sobral F (1982). Algumas considerações sobre a detecção dos talentos desportivos. Ludens, 6,8-13.

28. Vieira F, Fragoso I (in press). Reavaliação antropométrica da população infantil de Lisboa. Lisboa: CM Lisboa. 